\title{
Do revolucionário juvenil ao evolucionário geracional: aproximações e protagonismo social da geração $X$ à geração $Y$
}

\author{
Valeria Brandini ${ }^{1}$ \\ Recebido em: 01/09/2014. Aprovado em: 01/11/2014. Disponibilizado em: 26/12/2014 \\ 1. Valeria Brandini é Socióloga pela UNICAMP. Doutora e Mestre em Ciências da Comunicação pela USP. Pesquisadora e Profa. \\ de Comunicação da Faculdade Eniac.
}

\section{Resumo}

Este artigo constitui uma reflexão teórica sobre a Geração Y, ou Geração Internet, seu protagonismo na sociedade contemporânea e o processo de passagem de produtor cultural marginal a agente de inovação no grande mercado que esta desempenha atualmente, tendo como foco neste trabalho, a perspectiva, subsidiada em estudos sobre as gerações anteriores, de que este processo iniciara-se já na Geração X, que revelava-se como uma geração autoral pela apropriação das novas tecnologias de comunicação e produção, advento que consolidara-se e ampliara-se na Geração X.

Palavras-chave: reflexão teórica, Geração X, Geração X.

\begin{abstract}
This article constitutes a theoretical reflection about the Y Generation, or Generation Internet, it's protagonism in contemporary society and the process it plays actually, turning from marginal cultural producer to innovation agent in the wide market, having as the focus of this paper, the perspective, subsidized in previous generations studies, that this process had started in the Generation X, which revealed itself as an authorial generation by the appropriation of new communication and production technologies, advent consolidated and expanded in the Generation $Y$
\end{abstract}

Keywords: theoretical reflection, Generation X, Generation Y 


\section{Introdução}

No início dos anos 2000, o antropólogo Massimo Cannevacci chamava a atenção, em sua obra Culture eXtreme (CANEVACCI, 1999), para o caráter cada vez mais fluido e heterogêneo da juventude da época, a então chamada "Geração X". Ao categorizá-la como "eXtrema" (sic), a letra x em caixa alta faz uma alusão ‘a característica de indefinição da geração nascida entre os anos 1960 e final dos anos 1970, segundo o autor, uma geração Xterminada, que não se termina, não possui barreiras definidas, nem limites temporais, mas que se recria constantemente ao incorporar diferentes elementos culturais o tempo todo. A geração eXtrema estava, segundo Canevacci, perdida num mar de possibilidades onde o indivíduo, apropriando-se cada vez mais de papéis sociais diversos e novas possibilidades de ser e viver, tornava-se multivíduo ${ }^{1}$, um indivíduo múltiplo cuja identidade se forma a partir da adesão a diferentes grupos, experiências e vivências, transitando pela desterritorialidade urbana, cada vez mais imersa no nomadismo tecnológico da web.

Já no fim dos anos 1990, época em que Canevacci começara a escrever Culture eXtreme ${ }^{2}$, a internet começara a alterar as possibilidades de vivências e constituições identitárias dos jovens pela troca cada vez mais veloz, intensa e sobretudo, viável, de informações e perspectivas culturais. A noção de subcultura, com traços definidos de uma identidade coesa e determinada, institucionalizada como em grupos de estilo juvenis como punks, skinheads e hippies,

${ }^{1}$ Entrevista concedida por Massimo Canevacci `a autora em seu apartamento em Roma, Itália, em pesquisa de doutorado financiada com bolsa de pesquisa da FAPESP em 2001.

${ }^{2}$ Orientando posteriormente meu doutorado sanduíche (com auxílio FAPESP) sobre a relação entre moda e cultura urbana, na Universitá La Sapienza em 2001, que resultou na tese "Vestindo desintegrava-se ao agregar signos identitários de outros grupos, rompendo com as barreiras que definiam e segregavam os limites dos grupos em relação a outras subculturas (por intenção de seus próprios membros), na moderna urbe.

Antes do termo Geração Y, ou Millennials (termos gerados para definir a geração nascida entre 1980 e 2000, radicalmente influenciada pela internet) tomarem de assalto revistas e livros buscando delinear e categorizar a mencionada geração, a anterior, chamada de Geração X a partir de um termo criado pelo fotografo Frank Capa em 1950 e popularizado pelo romance de Douglas Coupland, "Geração X: contos para uma cultura acelerada", de 1991, já apresentava uma estreita relação com a globalização de culturas, em especial, ao que o sociólogo Otavio Ianni denominava desterritorialização de elementos culturais (IANNI, 1992) ${ }^{3}$ de um lado e por outro, a hibridização de estilos de vida, culturas de consumo e o deslocamento progressivo da ideia de pertencimento para uma esfera mais globalizante orientada por trocas culturais cada vez mais intensas entre jovens de diferentes lugares, padrões sociais e perspectivas sobre a realidade motivadas por afinidades eletivas e a busca por novidades, exotismo e uma abertura para a cultura e formas de ser e viver do Outro.

Este artigo se propõe a analisar, sob uma perspectiva sociológica e também comunicacional, a conceituação da chamada Geração Y, ou Geração Internet, menos como uma geração revolucionária, como tem sido aclamada pela mídia e senso comum ${ }^{4}$ e

a Rua, Moda, Cultura \& Metrópole”, defendida em 2003.

${ }^{3}$ A exemplo do fenômeno world music, dos anos 1990, onde estilos musicais e étnicos de diferentes nações tomaram de assalto a cena da música mundial

${ }^{4}$ Como em matéria publicada pela revista norteamericana Time, abordando a dita Geração Y 
mais como uma geração evolucionária, que aperfeiçoou comportamentos e formas de socialização influenciadas pela (ou situadas na) internet, concretizando, por meio do acesso ‘as novas tecnologias digitais, cada vez mais desenvolvidas e democratizadas, além de desejos, perspectivas e comportamentos que já faziam parte do universo simbólico e vivencial dos jovens da chamada Geração X.

A partir da revisitação a estudos realizados sobre a Geração X durante meu mestrado (BRANDINI, 1999) e também meu doutorado (BRANDINI, 2003) em Ciências da Comunicação na USP, numa abordagem sociológica sobre grupos de estilo juvenis e produções culturais como moda e música, visei traçar comparações elucidando similaridades, diferenças e processos de continuidade de comportamento e cultura entre esta geração e a atual Geração Y, (também conhecida como Geração Internet, onde a letra $\mathrm{Y}$ faz referência a esta) reunindo neste paper algumas observações e reflexões sobre o tema.

\section{O "X" da Questão "Y"}

A geração $\mathrm{X}$, em especial, os nascidos em meados dos anos 1970, já experienciava a 'policultura desterritorializada' CANEVACCI (2001): uma grande articulação entre elementos culturais e signos extraídos de diferentes meios, culturas e grupos, que gerava novas e diversas manifestações e bens culturais como música, entretenimento, formas de sociabilidade. Estes elementos culturais e signos derivavam, muitas vezes de grupos de estilo anteriores (ou subculturas) que utilizavam composições estéticos e padrões de comportamento específicos (como os grupos de estilo dos anos 1980, as chamadas tribos urbanas, por

como uma geração narcisista, porém extremamente inovadora e que, segundo a publicação, irá salvar a todos nós. Revista Time, parte da grande midia) adotados consensualmente por seus participantes para marcar identidades e definir territórios geográficos e simbólicos e que passavam, a partir de então, a transitar por um universo onde sua adesão e descarte eram cada vez mais efêmeros, fluidos, tornando-os obsoletos `a medida que as trocas simbólicas e de informação entre grupos se acelerava com o uso da internet, gerando o compartilhamento cada vez maior de novos signos e padrões de comportamento a serem acessados e adotados sem fronteiras geográficas, ou limites culturais.

A internet como espaço de compartilhamento e experimentações de realidades vividas e imaginárias já vinha assumindo um protagonismo entre os jovens dos anos 1990 por constituir de um lado um palco desterritorializado e simbólico de manifestações das inquietações, fantasias, trocas e processos relacionais juvenis e de outro por instaurar-se como um 'artefato cultural', que a partir de autores como SHAH (2005) e AMARAL (2009), pode ser entendido como um repositório orgânico de idéias em evolução constante, que quando apropriado por grupos e indivíduos de diferentes cosmologias culturais, é reconfigurado e assume novos contornos a partir da contribuição de novos usos e idéias. E é enquanto artefato cultural que o meio tornado mensagem (numa alusão ao conceito de "o meio é a mensagem", de Marshall McLuhan, 1974), passa a território emocional, sensorial, vivencial - um cosmos orgânico alimentado pela vivência do real transportada para a web, mas que também transporta, a partir do ethos cultural que se constitui em seu espaço de trocas relacionais, uma ética pautada em códigos de valores que se constituem organicamente no virtual e são

publicação de Maio de 2013. http://time.com/247/millennials-the-me-me-megeneration/ site visitado em agosto de 2014 
adotados na vida "real" pelos usuários de internet.

\section{Espaço vivencial}

Como espaço vivencial heterogêneo e democrático, a internet já contribuía, junto `a juventude dos anos 1990, para a consolidação de uma fluidez e descentramento que se iniciara na globalização cultural do fim dos anos 1980, com a queda do Muro de Berlim e esvaziamento da cultura de polarização do poder das duas grandes potências, Estados Unidos e União Soviética, gerada a partir da Guerra Fria. A descentralização do poder também atingia o cerne dos grupos de estilo juvenis, a partir dos anos 1990, em cenas juvenis como o Grunge, marcada pela era do alternativo na música (BRANDINI, 1999) e comportamento, a adoção constante de novos signos estéticos e estilos musicais, de composição indumentária, de comportamentos, o que a partir da segunda metade dos anos 2000, fez com que o grande mercado buscasse mapear, por meio de pesquisas baseadas em ciências métodos como antropologia, etnografia e semiótica, o universo simbólico e de tendências socioculturais dos grupos juvenis em busca de indicadores de comportamento e insights para estratégias de marketing, desenvolvimento de produtos e comunicação publicitária.

Segundo FINOT'TI, em sua tese sobre a contribuição do estudo de estilo de vida para o marketing, "O Estilo de Vida além de ser um dos fatores que influenciam o comportamento do consumidor, pode ser utilizado ainda como modelo alternativo de segmentação" (FINOTTI, 2009: 4). A chamada Geração X e, posteriormente, a Geração Y tornaram-se, para o grande mercado, um arcabouço de tendências de comportamento e consumo pelo processo de constante inovação estética, de signos e comportamentos, orientada, em grande parte pela possibilidade de trocas culturais, ideias e compartilhamento de elementos de alteridade de grupos, povos, culturas e mesmo mercados.

A dissolução de categorias hegemónicas de poder que predominou entre a juventude dos anos 1990 desarticulou a relação entre cultura dominante/cultura juvenil (BRANDINI, 1999), relação esta que balizou muito do comportamento de ruptura adotado pelas gerações juvenis do século XX. Se nos anos 1950, na emergência das culturas juvenis a partir da Geração Baby Boom, dos jovens nascidos logo após a Segunda Guerra Mundial, a dicotomia se dava entre a geração dos jovens buscando estruturar sua individualidade a partir da adoção de signos e comportamentos de ruptura, como o rock n' roll e os mais velhos, adultos, os pais que coibiam comportamentos e escolhas dos jovens, nos anos 1960 a contracultura estruturara-se a partir de uma relação com a chamada cultura burguesa (ROSZAK, 1972), a partir da Geração X os jovens começam a contornar a oposição junto aos mais velhos, ao mercado e ao status quo e desenvolver relações de reciprocidade, adentram o mercado que as gerações anteriores criticavam como opressor, ou 'careta' (sic) e passam a se relacionar com ele para viabilizar suas produções e objetivos, como no caso dos Yuppies dos anos 1980 e dos jovens músicos que no rock alternativo criaram selos autorais para gravarem suas músicas, rejeitadas por gravadoras, passando do status de músicos a produtores musicais e empresários.

A Geração Y pode ser vista como uma continuidade da Geração X neste aspecto, uma geração que desde cedo se apropriara das novas tecnologias digitais e eletrônicas, além de conhecimentos sobre gestão de empresas, marketing, engenharias, mas não para seguir carreiras corporativas como gostariam os pais das gerações anteriores, mas para viabilizarem suas produções culturais, digitais, de diferentes bens e serviços, desde aplicativos para ouvir música, até camisetas exóticas e 
divertidas, passando por serviços de pet care (cuidar de animais) divulgados por sites e blogs na internet criados por eles mesmos.

Don Tapscot , em sua obra "A hora da geração digital (2010) defende a idéia de que os jovens da Geração Y, ou Geração Internet, como quer o autor, estão transformando as instituições da vida moderna, da família ao mercado, substituindo uma cultura de controle e ordenação por uma cultura de capacitação, pois o duo mídia e mercado reflete valores da indústria e de seus proprietários, mas as novas mídias, por outro lado, dão o controle a todos os usuários. $\mathrm{O}$ autor pontua que pela primeira vez os jovens assumiram o controle de elementos essenciais para uma revolução nas comunicações e com isso, assumem cada vez mais o papel de agentes do processo de produção de bens e comunicações, pois diferentemente das gerações anteriores, que não tinham controle sobre as mídias e processos de comunicação de massa, eles se apropriam cada vez mais da produção e compartilhamentos de conteúdos, percepções, julgamentos e contestações - em grande profusão a marcas, organizações e produtos - de forma a enfraquecer o controle sobre a orientação do desejo e da indução `a aspiração de consumo por parte da grande industria e promover um processo orgânico de influência ativa e não passiva (como nas gerações da TV e mídia impressa) que reorienta o mercado, as formas de apreender o universo de valores $\mathrm{e}$ comportamentos destes jovens, de produzir, comunicar e distribuir bens tangíveis e intangíveis.

O argumento de Tapscott sobre a Geração Y reitera uma inferência que trabalháramos na tese "Vestindo a Rua, Moda, Cultura \& Metrópole (2003), onde abordamos o contexto da dissolução de categorias hegemônicas de poder que atravessa os anos 90, o qual vinha desarticulando a relação de confronto entre cultura dominante/cultura juvenil:
"Não podemos então pensar em pólos opostos, mas em estruturas de poder que competem continuamente, que transitam pela "desterritorialidade" da metrópole de forma fluida, mutante, em permanente movimento. Os movimentos efetuados no espaço imaterial das culturas juvenis atuais não obedecem mais à linearidade da oposição ou contrariedade em favor de algo, mas podem ser vistos como movimentos randômicos de uma metrópole cada vez mais caleidoscópica” (BRANDINI, 2003).

Se as gerações juvenis anteriores, como a geração Baby Boom se agregava em grupos de estilo juvenis para construir uma identidade juvenil compartilhada entre communitas, como os hippies, e nos anos 1970, os punks, visando assim estabelecer-se como força social num relacionamento diacrônico com "o mundo adulto", com a coletividade dos agentes em posição de autoridade e liderança, como pais, chefes, professores, buscando viabilizar suas produções culturais e mesmo comerciais `a margem do grande mercado, a partir da apropriação das novas tecnologias, a Geração $\mathrm{Y}$, "nativa" das novas tecnologias de comunicação e do universo digital, conseguiu articular o ímpeto, a audácia e a busca pelo novo, traços essenciais da adolescência, com a propriedade sobre a tecnologia, trazendo o viés autoral da Geração X para um patamar mais elevado, onde o produtor marginal torna-se produtor integrado ‘a dinâmica do grande mercado, chegando alguns, a tornarem-se "players" (termo utilizado em negócios para denominar um profissional competente, de grande talento, que se destaca), a exemplo de Mark Zuckerberg, criador do Facebook.

Um outro exemplo, neste caso, brasileiro, foi a empresa de consultoria de tendências juvenis Box 1824, que formada por dois sócios na faixa de vinte e dois anos, utilizou metodologias oriundas da 
antropologia e da semiótica para mapear, analisar e identificar tendências para grandes empresas brasileiras e multinacionais, a fim de gerar insights e orientações para a tomada de decisões estratégicas em negócios.

Não é `a toa que grandes empresas investem cada vez mais em incubadoras de start ups, processo no qual se oferece os pré requisitos para o desenvolvimento de uma companhia, como o espaço físico, expertise e contatos de negócios, alem do subsidio aos custos associados a funções administrativas e, mais recentemente, nas aceleradoras de startups, organizações onde, alem da estrutura das incubadoras, possui um processo de seleção com viés de alta competitividade, apresentação a grandes investidores, mentoring e um suporte de tempo limitado (BARREHAG, 2012), elementos que expressam o caráter de busca de alto desempenho e competitividade entre as startups, valorizando os jovens de ideias mais inovadoras e projetos idem.

\section{Considerações finais}

Se até a Geração $\mathrm{X}$ as produções e manifestações juvenis, elementos de inquietude renovadora, ruptura e geração de novas perspectivas e possibilidades eram apropriadas pelo grande mercado, desterritorializadas de seu sentido original e tornadas produto e tendência de consumo (a exemplo da moda inspirada nos grupos de estilo juvenis e esportes que tornaram-se febre de consumo de produtos e serviços inspirados nos comportamentos radicais de skatistas, bung jumpers e bikers), processo apreendido e estudado em nossa pesquisa de doutorado (BRANDINI, 2003) observamos nos dias de hoje uma rearticulação do papel dos jovens no mercado e na sociedade como um todo, onde a juventude passou de objeto de apropriação de tendências para agente de novos processos e mudanças no mercado.
O movimento observado a partir da Geração X, num processo evolucionário, vem tornando a juventude, inicialmente protagonista de insights e padrões comportamentais expropriados por agencias de publicidade e empresas (mesmo os selos dos músicos dos anos 1980-90, tinham suas bandas de maior repercussão cooptadas por grandes gravadoras), atualmente o grande agente de inovação no mundo dos negócios.

A partir dos nativos da Geração Y, inicialmente cooptados por grandes empresas para comporem um quadro de profissionais emergentes, os chamados 'millennials' são agora empreendedores e concorrentes de grande empresas, com potencial de competitividade em função, de um lado, da ruptura para com padrões, o que induz a processos de inovação, por trazer a visão de novas formas de perceber, fazer e relacionarse no mercado e de outro, da inserção destes jovens no universo do empreendedorismo, a fim de viabilizar ideias e projetos que outras gerações não teriam como desenvolver, pois não tinham acesso `as tecnologias atuais, que permitem democratização, inovação, diversidade e divulgação de novos produtos, processos e serviços criados pelos jovens.

Temos, portanto, neste processo evolucionário, da Geração X ‘a Y, a ruptura como padrão, geradora de tensões sociais e estranhamento, por trazer o inusitado e fora do status quo, o elemento mais valorizado pelo grande mercado para a sobrevivência e sucesso de empresas - a inovação - agora protagonizada mercadologicamente pelos jovens da Geração Y.

\section{Bibliografia}

1. AMARAL, Adriana. "Autonetnografia e inserção online: o papel do pesquisadorinsider nas práticas comunicacionais das subculturas da Web". revista Fronteiras - 
estudos midiáticos 11(1): 14-24, janeiro/abril 2009

2. BARREHAG, Lisa, Et. ali. "Accelerating Success: A Study of Seed Accelerators and Their Defining Characteristics”. Department of Technology Management and Economics. Division of Innovation Engineering and Management. Bachelor Thesis.

3. Chalmers University Of Technology. Gothenburg, Sweden. 2012

4. BRANDINI, Valeria. "Rock alternativo: do Underground a MTV (mercado cultural, produção e tendências do rock dos anos 90)". Dissertação de Mestrado defendida na Escola de Comunicações e artes da USP. Orientador: Waldenyr Caldas. MIMEO. São Paulo. 1999. 5. CANEVACCI, Massimo. Cultura eXtrema, Mutazione Giovanili tra i corpi delle metropoli. Roma. Meltemi editore. 1999 6. FINOTTI, Marcelo. "Contribuições Ao Estudo Dos Estilos De Vida: Comportamento de Compra e Uso de Crédito". Tese de doutorado defendida na Faculdades de Economia, Administração e Contabilidade da USP. Orientador: Celso Grisi. MIMEO. São Paulo, 2009.
7. IANNI, Octávio. "A desterritorialização", in A Sociedade Global. Campinas, Civilização Brasileira, 1992.

8. KEMP, Kênia. "Os grupos de estilo", in Grupos de Estilo Jovens: O Rock Underground e as Práticas (Contra) Culturais dos Grupos "Punks" e "Thrash" em São Paulo. Dissertação de Mestrado, UNICAMP, Campinas, 1993.

9. MATZA, David. "As tradições Ocultas da Juventude", em Sociologia da Juventude III. Rio de Janeiro, Zahar, 1980.

10. MCLUHAN, Marshall. "Os meios de comunicação: como extensões do homem". Ed. Cultrix, São Paulo. 1974.

11. ROSZAK, Theodore. "A contracultura". Petrópolis: Editora Vozes, 1972.

12. SHAH, Nishant. "PlayBlog: Pornography, performance and cyberspace. Cut-up. com Magazine". Holanda, V.2.5, issue 42, 24 set. 2005.

13. TAPSCOTT, Don. "A hora da geração digital: como os jovens que cresceram usando a internet estão mudando tudo, das empresas aos governos". Rio de Janeiro: Agir Negócios, 2010. 